\title{
On Intuitionistic Fuzzy Weakly m Generalized Continuous Mapping
}

\author{
K. Kadambavanam, PhD \\ PG and Research Department of Mathematics, \\ Sri Vasavi College, \\ Erode-638 316, \\ Tamilnadu, India.
}

\begin{abstract}
The purpose of this paper is to introduce and study the concepts of intuitionistic fuzzy weakly $\pi$ generalized continuous mappings defined on intuitionistic fuzzy topological space. Some of its properties are derived.
\end{abstract}

\section{Keywords}

Intuitionistic fuzzy topology, intuitionistic fuzzy weakly $\pi$ generalized closed set and open set, intuitionistic fuzzy weakly $\pi$ generalized continuous mappings, intuitionistic fuzzy $w \pi \mathrm{T}_{1 / 2}$ space and intuitionistic fuzzy $\mathrm{w} \pi \mathrm{gT} \mathrm{T}_{\mathrm{q}}$ space.

\section{Ams Classification Code (2000)}

54A40, 03 F55.

\section{INTRODUCTION}

The concept of fuzzy sets was introduced by Zadeh [16] in 1965. Then this concept was generalized into intuitionistic fuzzy (IF) by Atanassov [1] in 1986. After the introduction of IF sets, many research articles have been published in the study of examining and exploring, how far the basic concepts and theorems, defined in crisp sets and in fuzzy sets remain true in the new environment. The concept of fuzzy topology was introduced by Chang [3] in 1968. In 1997, Coker [4] initiated the concept of generalization of fuzzy topology into IF topology. The apprehension of semi closed, $\alpha$ closed, semi pre-closed, weakly closed had been introduced in his paper. Further their properties are derived.

In this paper, the concept of IF weakly $\pi$ generalized continuous mappings is introduced and studied with examples. The derivations of some of its properties are done. Illustrations are given to testify the derived results.

This paper is organized into five sections. In the first section historical development of the concepts were discussed. Second section is devoted for basic definitions and results, needed for this work. Section three discusses the IF weakly $\pi$ generalized continuous mappings. Suitable examples are given in each section. Application of the concepts introduced in section three is studied on $\mathrm{IFw}_{\mathrm{W}} \mathrm{T}_{1 / 2}$ space and $\mathrm{IFw}_{\mathrm{g}} \mathrm{gT}$ space into section four. Conclusion of this study is in section five.

\section{PRELIMINARIES}

Definition 2.1: Let $X$ be a non-empty crisp set. An intuitionistic fuzzy (IF) set $\mathrm{A}$ in $\mathrm{X}$ is defined as an object of the form [1]

$\mathrm{A}=\left\{<x, \vartheta_{\mathrm{A}}(\mathrm{x}), v_{\mathrm{A}}(\mathrm{x})>\mid x \in X\right\}$,

where the functions $]_{\mathrm{A}}(\mathrm{x}): \mathrm{X} \rightarrow[0,1]$ and

\author{
K. Vaithiyalingam \\ Assistant Professor \\ Department of Mathematics, \\ Kongu Engineering College, Perundurai, Erode- \\ 638 052, Tamilnadu, India.
}

$v_{A}(x): X \rightarrow[0,1]$ denote the degree of membership (namely $\Omega_{A}$ ) and the degree of non-membership (namely $v_{A}$ ) of each element $\mathrm{x} \in \mathrm{X}$ to the set $\mathrm{A}$, respectively, and $0 \leq$ $?_{A}(x)+v_{A}(x) \leq 1$ for each $x \in X$. The set of all intuitionistic fuzzy sets in $\mathrm{X}$ is denoted by $\operatorname{IFS}(\mathrm{X})$.

Definition 2.2: Let A and B be IFSs of the form [1],

$$
\begin{aligned}
& \mathrm{A}=\left\{<x, ?_{\mathrm{A}}(\mathrm{x}), v_{\mathrm{A}}(\mathrm{x})>\mid x \in X\right\}, \\
& \mathrm{B}=\left\{<x, ?_{\mathrm{B}}(\mathrm{x}), v_{\mathrm{B}}(\mathrm{x})>\mid x \in X\right\} .
\end{aligned}
$$

The operations $\wedge$ and $\vee$ are defined on $\vartheta_{A}(x), ?_{B}(x)$, $v_{\mathrm{A}}(\mathrm{x})$, and $v_{\mathrm{B}}(\mathrm{x})$ as follows,

$?_{\mathrm{A}}(\mathrm{x}) \wedge ?_{\mathrm{B}}(\mathrm{x})=\min \left\{?_{\mathrm{A}}(\mathrm{x}), ?_{\mathrm{B}}(\mathrm{x})\right\}$,

$v_{\mathrm{A}}(\mathrm{x}) \vee v_{\mathrm{B}}(\mathrm{x})=\max \left\{v_{\mathrm{A}}(\mathrm{x}), v_{\mathrm{B}}(\mathrm{x})\right\}$,

$?_{\mathrm{A}}(\mathrm{x}) \vee ?_{\mathrm{B}}(\mathrm{x})=\max \left\{?_{\mathrm{A}}(\mathrm{x}), ?_{\mathrm{B}}(\mathrm{x})\right\}$ and

$v_{\mathrm{A}}(\mathrm{x}) \wedge v_{\mathrm{B}}(\mathrm{x})=\min \left\{v_{\mathrm{A}}(\mathrm{x}), v_{\mathrm{B}}(\mathrm{x})\right\}$. Then,

i) $\mathrm{A} \subseteq \mathrm{B}$ if and only if $?_{\mathrm{A}}(\mathrm{x}) \leq ?_{\mathrm{B}}(\mathrm{x})$ and $\quad v_{\mathrm{A}}(\mathrm{x}) \geq$ $v_{\mathrm{B}}(\mathrm{x})$ for all $\mathrm{x} \in \mathrm{X}$, similarly $\mathrm{A} \supseteq \mathrm{B}$

can be defined,

ii) $\mathrm{A}=\mathrm{B}$ if and only if $\mathrm{A} \subseteq \mathrm{B}$ and $\mathrm{B} \subseteq \mathrm{A}$,

iii) $\mathrm{A}^{\mathrm{C}}=\left\{<x, v_{\mathrm{A}}(\mathrm{x}), ?_{\mathrm{A}}(\mathrm{x})>\mid x \in X\right\}$, here the membership grade of $\mathrm{x}$ in $\mathrm{A}$ is the non- membership grade of $\mathrm{x}$ in $\mathrm{A}^{\mathrm{C}}$ and vice versa,

iv) $\mathrm{A} \cap \mathrm{B}=\left\{<x, \square_{\mathrm{A}}(\mathrm{x}) \wedge \square_{\mathrm{B}}(\mathrm{x}), v_{\mathrm{A}}(\mathrm{x}) \vee \quad v_{\mathrm{B}}(\mathrm{x})>\right.$ $\mid x \in X\}$, and

v) $\mathrm{A} \cup \mathrm{B}=\left\{<x, ?_{\mathrm{A}}(\mathrm{x}) \vee ?_{\mathrm{B}}(\mathrm{x}), v_{\mathrm{A}}(\mathrm{x}) \wedge \quad v_{\mathrm{B}}(\mathrm{x})>\right.$ $\mid x \in X\}$.

For the sake of simplicity, the notation

$\mathrm{A}=\left\langle x, ?_{\mathrm{A}}, v_{\mathrm{A}}>\right.$ is used instead of

$\mathrm{A}=\left\{<x, ?_{\mathrm{A}}(\mathrm{x}), v_{\mathrm{A}}(\mathrm{x})>\mid x \in X\right\}$.

The intuitionistic fuzzy sets $0_{\sim}$ and $1_{\sim}$ are defined respectively as, $0_{\sim}=\{\langle x, 0,1\rangle \mid x \in X\}$ and

$1_{\sim}=\{\langle x, 1,0\rangle \mid x \in X\}$. The sets $0_{\sim}$ and $1_{\sim}$ are known as the empty set and the whole set of $X$ respectively.

Definition 2.3: An intuitionistic fuzzy topology (IFT) is a family $\tau$ of IFS defined on X satisfying the following axioms [4],
i) $0_{\sim}, 1_{\sim} \in \tau$,
ii) $G_{1} \cap G_{2} \in \tau$, for any $G_{1}, G_{2} \in \tau$, 
iii) $\cup G_{i} \in \tau$ for any arbitrary family $\left\{G_{i} \mid i \in J\right\} \subseteq \tau$.

Then the pair $(X, \tau)$ is called an intuitionistic fuzzy topological space (IFTS) and any IFS in $\tau$ is known as an intuitionistic fuzzy open set (IFOS) in X.

The complement $\mathrm{A}^{\mathrm{C}}$ of an IFOS, $\mathrm{A}$ in an IFTS $(\mathrm{X}, \tau)$ is called an intuitionistic fuzzy closed set (IFCS) in X.

Definition 2.4: Let $(X, \tau)$ be an IFTS and

$\mathrm{A}=\left\langle x, \mathrm{Q}_{\mathrm{A}}, v_{\mathrm{A}}\right\rangle$ be an IFS in X. Then the intuitionistic fuzzy closure and an intuitionistic fuzzy interior are defined by [4],

$$
\begin{aligned}
& \operatorname{cl}(A)=\cap\{G \mid G \text { is an IFCS in } X \text { and } A \subseteq G\}, \text { and } \\
& \quad \operatorname{int~}(A)=U\{K \mid K \text { is an IFOS in } X \text { and } K \subseteq A\} .
\end{aligned}
$$

Note that for any IFS, $A$ in $(X, \tau), \operatorname{cl}\left(A^{C}\right)=(\operatorname{int}(A))^{c}$ and $\operatorname{int}\left(\mathrm{A}^{\mathrm{c}}\right)=(\mathrm{cl}(\mathrm{A}))^{\mathrm{c}}$.

Definition 2.5: An IFS, $A=\left\langle x, ?_{A}, v_{A}\right\rangle$ in an $\operatorname{IFTS}(X, \tau)$ is said to be an

i) intuitionistic fuzzy closed set [4] (IFCS) in $\mathrm{X} \Leftrightarrow$ $\operatorname{cl}(\mathrm{A})=\mathrm{A}$, and

ii) intuitionistic fuzzy open set [4] (IFOS) in $\mathrm{X} \Leftrightarrow$ $\operatorname{int}(\mathrm{A})=\mathrm{A}$.

Definition 2.6: A subset $A$ of a space $(X, \tau)$ is called

i) regular open [11] if $\mathrm{A}=\operatorname{int}(\operatorname{cl}(\mathrm{A}))$, and

ii) $\pi$ open [11] if $A$ is the union of regular open sets, symbolically A is an IF $\pi$ OS in $\mathrm{X}$.

Definition 2.7: An IFS, $\mathrm{A}=\left\langle x, \vartheta_{\mathrm{A}}, v_{\mathrm{A}}\right\rangle$ in an $\operatorname{IFTS}(X, \tau)$ is said to be an

i) intuitionistic fuzzy semi closed set [5] (IFSCS) if $\operatorname{int}(\operatorname{cl}(\mathrm{A})) \subseteq \mathrm{A}$, and

ii) intuitionistic fuzzy semi open set [5] (IFSOS) if $\mathrm{A} \subseteq$ $\operatorname{cl}(\operatorname{int}(\mathrm{A}))$.

Definition 2.8: Let $A$ be an IFS of an IFTS $(X, \tau)$. Then the semi closure of $A(\operatorname{scl}(A))$ and semi interior of $A(\operatorname{sint}(A))$ are defined as [14],

$\operatorname{scl}(A)=\cap\{G \mid G$ is an IFSCS in $X$ and $A \subseteq G\}$, and $\operatorname{sint}(\mathrm{A})=U\{\mathrm{~K} \mid \mathrm{K}$ is an IFSOS in $\mathrm{X}$ and $\mathrm{K} \subseteq \mathrm{A}\}$.

Result 2.1: Let $A$ be an IFS in $(X, \tau)$, then [12]

i) $\operatorname{scl}(\mathrm{A})=\mathrm{A} \cup \operatorname{int}(\operatorname{cl}(\mathrm{A}))$, and

ii) $\operatorname{sint}(\mathrm{A})=\mathrm{A} \cap \operatorname{cl}(\operatorname{int}(\mathrm{A}))$.

Definition 2.9: An IFS $A=\left\langle x, \vartheta_{A}, v_{A}\right\rangle$ in an $\operatorname{IFTS}(X, \tau)$ is said to be an

i) intuitionistic fuzzy $\alpha$ closed set [5] (IF $\alpha \mathrm{CS})$ if $\operatorname{cl}(\operatorname{int}(\operatorname{cl}(A))) \subseteq A$, and

ii) intuitionistic fuzzy $\alpha$ open set [5] (IF $\alpha \mathrm{OS})$ if $\mathrm{A} \subseteq$ $\operatorname{int}(\operatorname{cl}(\operatorname{int}(\mathrm{A})))$.
Definition 2.10: Let $A=\left\langle x\right.$, ? $\left._{A}, v_{A}\right\rangle$ be an IFS of an IFTS $(X, \tau)$. Then the $\alpha$ closure of $A(\alpha \operatorname{cl}(A))$ and $\alpha$ interior of $A(\alpha \operatorname{int}(A))$ are defined as [9], $\alpha \operatorname{cl}(\mathrm{A})=\cap\{\mathrm{G} \mid \mathrm{G}$ is an $\mathrm{IF} \alpha \mathrm{CS}$ in $\mathrm{X}$ and $\mathrm{A} \subseteq \mathrm{G}\}$, $\alpha \operatorname{int}(A)=U\{K \mid K$ is an IF $\alpha O S$ in $X$ and $K \subseteq A\}$.

Result 2.2: Let $A$ be an IFS in $(X, \tau)$, then [9]

i) $\alpha \operatorname{cl}(\mathrm{A})=\mathrm{A} \cup \operatorname{cl}(\operatorname{int}(\operatorname{cl}(\mathrm{A})))$, and

ii) $\alpha \operatorname{int}(\mathrm{A})=\mathrm{A} \cap \operatorname{int}(\operatorname{cl}(\operatorname{int}(\mathrm{A})))$.

Definition 2.11: An IFS, $A=\left\langle x\right.$, 目, $v_{A}>$ in an $\operatorname{IFTS}(X, \tau)$ is said to be an

i) intuitionistic fuzzy pre-closed set [5] (IFPCS) if, $\operatorname{cl}(\operatorname{int}(\mathrm{A})) \subseteq \mathrm{A}$

ii) intuitionistic fuzzy regular closed set [5] (IFRCS) if, $\operatorname{cl}(\operatorname{int}(\mathrm{A}))=\mathrm{A}$,

iii)intuitionistic fuzzy generalized closed set [13]

(IFGCS) if, $\operatorname{cl}(\mathrm{A}) \subseteq \mathrm{U}$ whenever $\mathrm{A} \subseteq \mathrm{U}, \mathrm{U}$ is an IFOS in $\mathrm{X}$,

iv)intuitionistic fuzzy generalized semi closed set [10]

(IFGSCS) if, $\operatorname{scl}(\mathrm{A}) \subseteq \mathrm{U}$ whenever $\mathrm{A} \subseteq \mathrm{U}, \mathrm{U}$ is an IFOS in $\mathrm{X}$

v) intuitionistic fuzzy $\alpha$ generalized closed set [9]

(IF $\alpha \mathrm{GCS})$ if, $\alpha \mathrm{cl}(\mathrm{A}) \subseteq \mathrm{U}$ whenever $\mathrm{A} \subseteq \mathrm{U}, \mathrm{U}$ is an IFOS in X.

Definition 2.12: An IFS, A is said to be an intuitionistic fuzzy weakly $\pi$ generalized closed set [7] (IFW $\pi \mathrm{GCS}$ ) in $(\mathrm{X}, \tau)$, if $\operatorname{cl}(\operatorname{int}(\mathrm{A})) \subseteq \mathrm{U}$ whenever $\mathrm{A} \subseteq \mathrm{U}$ and $\mathrm{U}$ is an $\mathrm{IF} \pi \mathrm{OS}$ in $\mathrm{X}$.

The family of all IFW $\pi$ GCS of an IFTS $(X, \tau)$ is denoted by $\mathrm{IFW} \pi \mathrm{GCS}(\mathrm{X})$.

Result 2.3: Every IFCS, IFaCS, IFGCS, IFRCS, IFPCS, IF $\alpha$ GCS are IFW $\pi$ GCS [7] but the converse need not be true.

Definition 2.13: An IFS, A is said to be an intuitionistic fuzzy weakly $\pi$ generalized open set [7] (IFW $\pi \mathrm{GOS}$ ) in (X, $\tau$ ) if, the complement $\mathrm{A}^{\mathrm{c}}$ is an IFW $\pi \mathrm{GOS}$ in $\mathrm{X}$.

The family of all IFW $\pi$ GOS of an IFTS $(X, \tau)$ is denoted by IFW $\pi$ GOS $(\mathrm{X})$

Definition 2.14: An IFTS $(X, \tau)$ is called an intuitionistic fuzzy $w \pi \mathrm{T}_{1 / 2}$ space (IF $w \pi \mathrm{T}_{1 / 2}$ ) [7], if every IFW $\pi$ GCS in X is an IFCS in X.

Definition 2.15: An IFTS $(X, \tau)$ is called an intuitionistic fuzzy $\mathrm{w} \mathrm{gT} \mathrm{T}_{\mathrm{q}}$ space $\left(\mathrm{IF} \mathrm{w} \pi \mathrm{gT} \mathrm{q}_{\mathrm{q}}\right)$ [7], where

$0<\mathrm{q}<1$, if every IFW $\pi$ GCS in $\mathrm{X}$ is an IFPCS in $\mathrm{X}$.

Definition 2.16: Let $\mathrm{f}$ be a mapping from an IFTS $(X, \tau)$ into $\operatorname{IFTS}(\mathrm{Y}, \sigma)$. Then $\mathrm{f}$ is said to be intuitionistic fuzzy continuous [5] (IF cts) if, $\mathrm{f}^{-1}(\mathrm{~B}) \in \operatorname{IFOS}(\mathrm{X})$ for every $\mathrm{B} \in$ $\sigma$. 
Definition 2.17: Let $f$ be a mapping from an IFTS $(X, \tau)$ into $\operatorname{IFTS}(\mathrm{Y}, \sigma)$. Then $\mathrm{f}$ is said to be

i) intuitionistic fuzzy semi continuous [15] (IFS cts) if, $\mathrm{f}^{-1}(\mathrm{~B}) \in \operatorname{IFSO}(\mathrm{X})$ for every $\mathrm{B} \in \sigma$,

ii) intuitionistic fuzzy $\alpha$ continuous [15] (IF $\alpha$ cts) if, $\mathrm{f}^{-1}(\mathrm{~B}) \in \mathrm{IF} \alpha \mathrm{O}(\mathrm{X})$ for every $\mathrm{B} \in \sigma$,

iii)intuitionistic fuzzy pre continuous [15] (IFP cts) if, $\mathrm{f}^{-1}(\mathrm{~B}) \in \operatorname{IFPO}(\mathrm{X})$ for every B $\in \sigma$,

iv)intuitionistic fuzzy regular continuous [15] (IFR cts)

if, $\mathrm{f}^{-1}(\mathrm{~B}) \in \operatorname{IFRO}(\mathrm{X})$ for every $\mathrm{B} \in \sigma$.

Definition 2.18: Let $f$ be a mapping from an IFTS $(X, \tau)$ into IFTS $(Y, \sigma)$. Then $f$ is said to be intuitionistic fuzzy generalized continuous [10]

(IFG cts) if, $\mathrm{f}^{-1}(\mathrm{~B}) \in$ IFGCS (X) for every IFCS, B in Y.

Definition 2.19: A mapping $f:(X, \tau) \rightarrow(Y, \sigma)$ is called intuitionistic fuzzy generalized semi continuous [9] (IFGS cts) if, $f^{-1}(B)$ is an IFGSCS in $(X, \tau)$ for every IFCS, B of $(Y, \sigma)$.

Definition 2.20: A mapping $\mathrm{f}:(\mathrm{X}, \tau) \rightarrow(\mathrm{Y}, \sigma)$ is called intuitionistic fuzzy $\alpha$ generalized continuous [9]

(IF $\alpha$ GS cts) if, $\mathrm{f}^{-1}(\mathrm{~B})$ is an IF $\alpha \mathrm{GCS}$ in $(\mathrm{X}, \tau)$ for every IFCS, B of $(Y, \sigma)$.

\section{INTUITIONISTIC FUZZY WEAKLY $\pi$ GENERALIZED CONTINUOUS MAPPINGS}

In this section, intuitionistic fuzzy weakly $\pi$ generalized continuous mappings is defined. Some of its properties are derived.

Definition 3.1: A mapping $\mathrm{f}:(\mathrm{X}, \tau) \rightarrow(\mathrm{Y}, \sigma)$ is called an intuitionistic fuzzy weakly $\pi$ generalized continuous mapping (IFW $\pi \mathrm{G}$ cts) if, $\mathrm{f}^{-1}(\mathrm{~B})$ is an IFW $\pi \mathrm{GCS}$ in $(\mathrm{X}, \tau)$ for every IFCS, B of $(Y, \sigma)$

Example 3.1: Let $X=\{a, b\}, Y=\{u, v\}$ and

$\mathrm{G}_{1}=\langle x,(0.2,0.2),(0.6,0.7)\rangle$,

$\mathrm{G}_{2}=\langle y,(0.6,0.7),(0.4,0.2)>$. Then

$\tau=\left\{0_{\sim}, G_{1}, 1_{\sim}\right\}$ and $\sigma=\left\{0_{\sim}, G_{2}, 1_{\sim}\right\}$ are IFTs on $X$ and $\mathrm{Y}$ respectively. Define a mapping

$\mathrm{f:}(\mathrm{X}, \tau) \rightarrow(\mathrm{Y}, \sigma)$ by $\mathrm{f}(\mathrm{a})=\mathrm{u}$ and $\mathrm{f}(\mathrm{b})=\mathrm{v}$. Then $\mathrm{f}$ is an IFW $\pi \mathrm{G}$ continuous mapping.

Proposition 3.1: Every IF continuous mapping is an IFW $\pi \mathrm{G}$ continuous mapping but not conversely.

Proof: Let $\mathrm{f}:(\mathrm{X}, \tau) \rightarrow(\mathrm{Y}, \sigma)$ be an IF continuous mapping. Let $B$ be an IFCS in Y. Since $f$ is IF continuous mapping, $\mathrm{f}^{-1}(\mathrm{~B})$ is an IFCS in X. Since every IFCS is an IFW $\pi \mathrm{GCS}$, $\mathrm{f}^{-1}(\mathrm{~B})$ is an IFW $\pi \mathrm{GCS}$ in $\mathrm{X}$. Therefore $\mathrm{f}$ is an IFW $\pi \mathrm{G}$ continuous mapping.

Example 3.2: Let $X=\{a, b\}, Y=\{u, v\}$ and

$$
\begin{aligned}
& \mathrm{G}_{1}=\langle x,(0.1,0.2),(0.8,0.7)>, \\
& \mathrm{G}_{2}=\langle y,(0.8,0.7),(0.1,0.3)>\text {. Then }
\end{aligned}
$$

$\tau=\left\{0_{\sim}, \mathrm{G}_{1}, 1_{\sim}\right\}$ and $\sigma=\left\{0_{\sim}, \mathrm{G}_{2}, 1_{\sim}\right\}$ are IFTs on $\mathrm{X}$ and $\mathrm{Y}$ respectively. Define a mapping

$\mathrm{f:}(\mathrm{X}, \tau) \rightarrow(\mathrm{Y}, \sigma)$ by $\mathrm{f}(\mathrm{a})=\mathrm{u}$ and $\mathrm{f}(\mathrm{b})=\mathrm{v}$. The IFS, $\mathrm{B}=<$ $y,(0.1,0.3),(0.8,0.7)>$ is IFCS in Y. Then $\mathrm{f}^{-1}(\mathrm{~B})$ is IFW $\pi$ GCS in $X$, but not IFCS in X. Therefore $f$ is an IFW $\pi \mathrm{G}$ continuous mapping but not an IF continuous mapping.

Proposition 3.2: Every IF $\alpha$ continuous mapping is an IFW $\pi \mathrm{G}$ continuous mapping but not conversely.

Proof: Let $\mathrm{f:}(\mathrm{X}, \tau) \rightarrow(\mathrm{Y}, \sigma)$ be an $\mathrm{IF} \alpha$ continuous mapping. Let $B$ be an IFCS in $Y$. Then by definition $f^{-1}(B)$ is an IF $\alpha C S$ in $X$. Since every IF $\alpha C S$ is an IFW $\pi G C S, f^{-1}(B)$ is an IFW $\pi \mathrm{GCS}$ in $\mathrm{X}$. Thus $\mathrm{f}$ is an IFW $\pi \mathrm{G}$ continuous mapping.

Example 3.3: Let $X=\{a, b\}, Y=\{u, v\}$ and

$\mathrm{G}_{1}=\langle x,(0.4,0.3),(0.6,0.5)>$,

$\mathrm{G}_{2}=<y,(0.2,0.3),(0.5,0.4)>$. Then

$\tau=\left\{0_{\sim}, G_{1}, 1_{\sim}\right\}$ and $\sigma=\left\{0_{\sim}, G_{2}, 1_{\sim}\right\}$ are IFTs on $X$ and $Y$ respectively. Define a mapping

$\mathrm{f:}(\mathrm{X}, \tau) \rightarrow(\mathrm{Y}, \sigma)$ by $\mathrm{f}(\mathrm{a})=\mathrm{u}$ and $\mathrm{f}(\mathrm{b})=\mathrm{v}$. The IFS, $\mathrm{B}=<$ $y,(0.5,0.4),(0.2,0.3)>$ is IFCS in Y. Then $\mathrm{f}^{-1}(\mathrm{~B})$ is IFW $\pi$ GCS in $\mathrm{X}$, but not IF $\alpha \mathrm{CS}$ in $\mathrm{X}$. Then $\mathrm{f}$ is an IFW $\pi \mathrm{G}$ continuous mapping but not an IF $\alpha$ continuous mapping.

Proposition 3.3: Every IFR continuous mapping is an $\mathrm{IFW} \pi \mathrm{G}$ continuous mapping but not conversely.

Proof: Let $\mathrm{f}:(\mathrm{X}, \tau) \rightarrow(\mathrm{Y}, \sigma)$ be an IFR continuous mapping. Let $B$ be an IFCS in $Y$. Then by definition $f^{-1}(B)$ is an IFRCS in X. Since every IFRCS is an IFW $\pi G C S, \mathrm{f}^{-1}(\mathrm{~B})$ is an IFW $\pi \mathrm{GCS}$ in $\mathrm{X}$. So, $\mathrm{f}$ is an IFW $\pi \mathrm{G}$ continuous mapping.

Example 3.4: Let $X=\{a, b\}, Y=\{u, v\}$ and

$$
\begin{aligned}
& \mathrm{G}_{1}=\langle x,(0.5,0.4),(0.4,0.5)>, \\
& \mathrm{G}_{2}=\langle y,(0.5,0.5),(0.4,0.3)>\text {. Then }
\end{aligned}
$$

$\tau=\left\{0_{\sim}, \mathrm{G}_{1}, 1_{\sim}\right\}$ and $\sigma=\left\{0_{\sim}, \mathrm{G}_{2}, 1_{\sim}\right\}$ are IFTs on $\mathrm{X}$ and $Y$ respectively. Define a mapping

$\mathrm{f:}(\mathrm{X}, \tau) \rightarrow(\mathrm{Y}, \sigma)$ by $\mathrm{f}(\mathrm{a})=\mathrm{u}$ and $\mathrm{f}(\mathrm{b})=\mathrm{v}$. The IFS, $\mathrm{B}=<$ $y,(0.4,0.3),(0.5,0.5)>$ is IFCS in Y. Then $\mathrm{f}^{-1}(\mathrm{~B})$ is IFW $\pi \mathrm{GCS}$ in $\mathrm{X}$, but not IFRCS in $\mathrm{X}$. Therefore $\mathrm{f}$ is IFW $\pi \mathrm{G}$ continuous mapping but not an IFR continuous mapping.

Proposition 3.4: Every IFP continuous mapping is an IFW $\pi \mathrm{G}$ continuous mapping but not conversely.

Proof: Let $\mathrm{f}:(\mathrm{X}, \tau) \rightarrow(\mathrm{Y}, \sigma)$ be an IFP continuous mapping. Let $B$ be an IFCS in Y. Then $f^{-1}(B)$ is an IFPCS in $\mathrm{X}$. Since every IFPCS is an IFW $\pi \mathrm{GCS}, \mathrm{f}^{-1}(\mathrm{~B})$ is an $\mathrm{IFW} \pi \mathrm{GCS}$ in $\mathrm{X}$. Therefore $\mathrm{f}$ is an IFW $\pi \mathrm{G}$ continuous mapping.

Example 3.5: Let $X=\{a, b\}, Y=\{u, v\}$ and

$$
\begin{aligned}
& \mathrm{G}_{1}=\langle x,(0.4,0.3),(0.6,0.7)\rangle, \\
& \mathrm{G}_{2}=\langle y,(0.6,0.4),(0.4,0.4)\rangle .
\end{aligned}
$$

Then $\tau=\left\{0_{\sim}, \mathrm{G}_{1}, 1_{\sim}\right\}$ and $\sigma=\left\{0_{\sim}, \mathrm{G}_{2}, 1_{\sim}\right\}$ are IFTs on $\mathrm{X}$ and $\mathrm{Y}$ respectively. Define a mapping

$\mathrm{f}:(\mathrm{X}, \tau) \rightarrow(\mathrm{Y}, \sigma)$ by $\mathrm{f}(\mathrm{a})=\mathrm{u}$ and $\mathrm{f}(\mathrm{b})=\mathrm{v}$. The IFS, $\mathrm{B}=<$ $y,(0.4,0.4),(0.6,0.4)>$ is IFCS in Y. Then $\mathrm{f}^{-1}(\mathrm{~B})$ is 
IFW $\pi$ GCS in $\mathrm{X}$, but not IFPCS in $\mathrm{X}$. Therefore $\mathrm{f}$ is IFW $\pi \mathrm{G}$ continuous mapping but not an IFP continuous mapping.

Proposition 3.5: Every IFG continuous mapping is an IFW $\pi \mathrm{G}$ continuous mapping but not conversely.

Proof: Let $\mathrm{f}:(\mathrm{X}, \tau) \rightarrow(\mathrm{Y}, \sigma)$ be an IFG continuous mapping. Let $B$ be an IFCS in $Y$. Since $f$ is an IFG continuous mapping, $\mathrm{f}^{-1}(\mathrm{~B})$ is an IFGCS in X. Since every IFGCS is an IFW $\pi \mathrm{GCS}, \mathrm{f}^{-1}(\mathrm{~B})$ is an IFW $\pi \mathrm{GCS}$ in $\mathrm{X}$. Thus $\mathrm{f}$ is an IFW $\pi \mathrm{G}$ continuous mapping.

Example 3.6: Let $X=\{a, b\}, Y=\{u, v\}$ and $\mathrm{G}_{1}=\langle x,(0.2,0.3),(0.7,0.6)\rangle$, $\mathrm{G}_{2}=<y,(0.8,0.7),(0.2,0.2)>$. $\left\{0_{\sim}, \mathrm{G}_{1}, 1_{\sim}\right\}$ and $\sigma=\left\{0_{\sim}, \mathrm{G}_{2}, 1_{\sim}\right\}$ are IFTs on $\mathrm{X}$ and $\mathrm{Y}$ respectively. Define a mapping

$\mathrm{f:}(\mathrm{X}, \tau) \rightarrow(\mathrm{Y}, \sigma)$ by $\mathrm{f}(\mathrm{a})=\mathrm{u}$ and $\mathrm{f}(\mathrm{b})=\mathrm{v}$. The IFS, $\mathrm{B}=<$ $y,(0.2,0.2),(0.8,0.7)>$ is IFCS in $Y, f^{-1}(B)$ is IFW $\pi$ GCS in $X$ but not IFGCS in $X$. Therefore $f$ is IFW $\pi G$ continuous mapping but not an IFG continuous mapping.

Proposition 3.6: Every IF $\alpha \mathrm{G}$ continuous mapping is an IFW $\pi \mathrm{G}$ continuous mapping but not conversely.

Proof: Let $\mathrm{f}:(\mathrm{X}, \tau) \rightarrow(\mathrm{Y}, \sigma)$ be an $\mathrm{IF} \alpha \mathrm{G}$ continuous mapping. Let $B$ be an IFCS in Y. Then by definition, $f^{-1}(B)$ is an IF $\alpha$ GCS in X. Since every IF $\alpha \mathrm{GCS}$ is an IFW $\pi \mathrm{GCS}$, $\mathrm{f}^{-1}(\mathrm{~B})$ is an IFW $\pi \mathrm{GCS}$ in $\mathrm{X}$. So, $\mathrm{f}$ is an IFW $\pi \mathrm{G}$ continuous mapping.

Example 3.7: Let $X=\{a, b\}, Y=\{u, v\}$ and

$\mathrm{G}_{1}=\langle x,(0.4,0.6),(0.2,0.2)>$,

$\mathrm{G}_{2}=<y,(0.6,0.2),(0.4,0.3)>$.

Then $\tau=\{$

$\left.0_{\sim}, \mathrm{G}_{1}, 1_{\sim}\right\}$ and $\sigma=\left\{0_{\sim}, \mathrm{G}_{2}, 1_{\sim}\right\}$ are IFTs on $\mathrm{X}$ and $\mathrm{Y}$ respectively. Define a mapping

$f:(X, \tau) \rightarrow(Y, \sigma)$ by $f(a)=u$ and $f(b)=v$. The IFS, $B=<$ $y,(0.4,0.3),(0.6,0.2)>$ is IFCS in Y. Then $\mathrm{f}^{-1}(\mathrm{~B})$ is IFW $\pi$ GCS in X, but not IF $\alpha$ GCS in X. Therefore $f$ is IFW $\pi G$ continuous mapping but not an $\mathrm{IF} \alpha \mathrm{G}$ continuous mapping.

Remark 3.1: IFS continuous mapping and IFW $\pi \mathrm{G}$ continuous mapping are independent to each other.

Example 3.8: Let $X=\{a, b\}, Y=\{u, v\}$ and

$\mathrm{G}_{1}=\langle x,(0.4,0.3),(0.6,0.7)>$,

$\mathrm{G}_{2}=<y,(0.6,0.7),(0.4,0.3)>$.

Then $\tau=$ $\left\{0_{\sim}, \mathrm{G}_{1}, 1_{\sim}\right\}$ and $\sigma=\left\{0_{\sim}, \mathrm{G}_{2}, 1_{\sim}\right\}$ are IFTs on $\mathrm{X}$ and $\mathrm{Y}$ respectively. Define a mapping

$\mathrm{f:}(\mathrm{X}, \tau) \rightarrow(\mathrm{Y}, \sigma)$ by $\mathrm{f}(\mathrm{a})=\mathrm{u}$ and $\mathrm{f}(\mathrm{b})=\mathrm{v}$. Then $\mathrm{f}$ is IFS continuous mapping but not an IFW $\pi \mathrm{G}$ continuous mapping, since $\mathrm{B}=\langle y,(0.4,0.3),(0.6,0.2)\rangle$ is an IFSCS in $\mathrm{Y}$, but $\mathrm{f}^{-1}(\mathrm{~B})=\langle x,(0.4,0.3),(0.6,0.2)\rangle$ is not an IFW $\pi \mathrm{GCS}$ in $\mathrm{X}$.

Example 3.9: Let $X=\{a, b\}, Y=\{u, v\}$ and

$\mathrm{G}_{1}=\langle x,(0.9,0.7),(0.1,0.2)>$,

$\mathrm{G}_{2}=<y,(0.3,0.4),(0.7,0.6)>$.

Then $\tau=$

$\left\{0_{\sim}, \mathrm{G}_{1}, 1_{\sim}\right\}$ and $\sigma=\left\{0_{\sim}, \mathrm{G}_{2}, 1_{\sim}\right\}$ are IFTs on $\mathrm{X}$ and $\mathrm{Y}$ respectively. Define a mapping
$f:(X, \tau) \rightarrow(Y, \sigma)$ by $f(a)=u$ and $f(b)=v$. Then $f$ is IFW $\pi G$ continuous mapping, but not an IFS continuous mapping, since $\mathrm{B}=\langle y,(0.7,0.6),(0.3,0.4)\rangle$ is an IFW $\pi \mathrm{GCS}$ in $\mathrm{Y}$, but $\mathrm{f}^{-1}(\mathrm{~B})=\langle x,(0.7,0.6),(0.3,0.4)\rangle$ is not an IFSCS in $\mathrm{X}$.

Remark 3.2: IFGS continuous mapping and IFW $\pi \mathrm{G}$ continuous mapping are independent to each other.

Example 3.10: Let $\mathrm{X}=\{\mathrm{a}, \mathrm{b}\}, \mathrm{Y}=\{\mathrm{u}, \mathrm{v}\}$ and $\mathrm{G}_{1}=<$ $x,(0.2,0.3),(0.5,0.5)>$,

$\mathrm{G}_{2}=<y,(0.5,0.5),(0.2,0.3)>$. Then

$\tau=\left\{0_{\sim}, \mathrm{G}_{1}, 1_{\sim}\right\}$ and $\sigma=\left\{0_{\sim}, \mathrm{G}_{2}, 1_{\sim}\right\}$ are IFTs on $\mathrm{X}$ and $\mathrm{Y}$ respectively. Define a mapping

$\mathrm{f:}(\mathrm{X}, \tau) \rightarrow(\mathrm{Y}, \sigma)$ by $\mathrm{f}(\mathrm{a})=\mathrm{u}$ and $\mathrm{f}(\mathrm{b})=\mathrm{v}$. Then $\mathrm{f}$ is IFGS continuous mapping, but not an IFW $\pi \mathrm{G}$ continuous mapping, since $\mathrm{B}=\langle y,(0.2,0.3),(0.5,0.5)\rangle$ is an IFGSCS in $\mathrm{Y}$, but $\mathrm{f}^{-1}(\mathrm{~B})=\langle x,(0.2,0.3),(0.5,0.5)\rangle$ is not an IFW $\pi \mathrm{GCS}$ in $\mathrm{X}$.

Example 3.11: Let $\mathrm{X}=\{\mathrm{a}, \mathrm{b}\}, \mathrm{Y}=\{\mathrm{u}, \mathrm{v}\}$ and $\mathrm{G}_{1}=<$ $x,(0.5,0.6),(0.2,0.2)>$,

$\mathrm{G}_{2}=\langle y,(0.6,0.6),(0.3,0.2)>$.

Then $\tau=$ $\left\{0_{\sim}, \mathrm{G}_{1}, 1_{\sim}\right\}$ and $\sigma=\left\{0_{\sim}, \mathrm{G}_{2}, 1_{\sim}\right\}$ are IFTs on $\mathrm{X}$ and $\mathrm{Y}$ respectively. Define a mapping

$f:(X, \tau) \rightarrow(Y, \sigma)$ by $f(a)=u$ and $f(b)=v$. Then $f$ is IFW $\pi G$ continuous mapping, but not an IFGS continuous mapping, since $\mathrm{B}=\langle y,(0.3,0.2),(0.6,0.6)\rangle$ is an IFW $\pi \mathrm{GCS}$ in $\mathrm{Y}$ but $\mathrm{f}^{-1}(\mathrm{~B})=\langle x,(0.3,0.2),(0.6,0.6)\rangle$ is not an IFGSCS in $\mathrm{X}$.

Remark 3.3: The derived relationship among the terms can be schematically presented as follows.
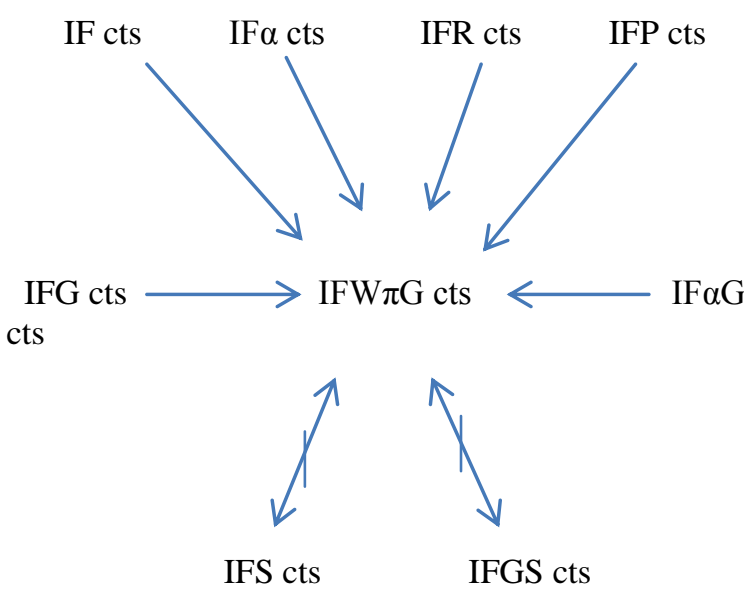

Fig.3.1 Relationships between the intuitionistic fuzzy weakly $\pi$ generalized continuous mapping, and the other existing continuous mapping on intuitionistic fuzzy closed sets. 


\section{APPLICATIONS OF INTUITIONISTIC FUZZY WEAKLY $\pi$ GENERALIZED CLOSED MAPPING}

Proposition 4.1: A mapping $\mathrm{f}:(\mathrm{X}, \tau) \rightarrow(\mathrm{Y}, \sigma)$ is $\mathrm{IFW} \pi \mathrm{G}$ continuous, then the inverse image of each IFOS in $\mathrm{Y}$ is an IFW $\pi$ GOS in $\mathrm{X}$.

Proof: Let $\mathrm{B}$ be an IFOS in Y. This implies $\mathrm{B}^{\mathrm{c}}$ is IFCS in $\mathrm{Y}$. Since $\mathrm{f}$ is $\mathrm{IFW} \pi \mathrm{G}$ continuous, $\mathrm{f}^{-1}\left(\mathrm{~B}^{\mathrm{c}}\right)$ is IFW $\pi \mathrm{GCS}$ in $\mathrm{X}$. Since $\mathrm{f}^{-1}\left(B^{c}\right)=\left(f^{-1}(B)\right)^{c}, f^{-1}(B)$ is an IFW $\pi G O S$ in $X$.

Proposition 4.2: Let $\mathrm{f}: \mathrm{X} \rightarrow \mathrm{Y}$ be an $\mathrm{IFW} \pi \mathrm{G}$ continuous mapping and $X$ be an $I F w \pi T_{1 / 2}$ space. Then $f$ is an IF continuous mapping.

Proof: Let X be an IFw $\pi \mathrm{T}_{1 / 2}$ space and $\mathrm{B}$ be an IFCS in Y. Then by definition (2.14), $\mathrm{f}^{-1}(\mathrm{~B})$ is an IFW $\pi \mathrm{GCS}$ in X. So, $\mathrm{f}^{-1}(\mathrm{~B})$ is an IFCS in $\mathrm{X}$. Therefore $\mathrm{f}$ is an IF continuous mapping.

Proposition 4.3: Let $\mathrm{f}: \mathrm{X} \rightarrow \mathrm{Y}$ be an IFW $\pi \mathrm{G}$ continuous mapping and $\mathrm{X}$ be an IFw $\pi \mathrm{gT}_{\mathrm{q}}$ space, where $0<\mathrm{q}<1$. Then $\mathrm{f}$ is an IFG continuous mapping.

Proof: Let $\mathrm{X}$ be an IFw $\mathrm{ggT}_{\mathrm{q}}$ space, $\mathrm{B}$ be an IFCS in Y. Then by definition (2.15), $\mathrm{f}^{-1}(\mathrm{~B})$ is an IFW $\pi \mathrm{GCS}$ in X. So, $\mathrm{f}^{-1}(\mathrm{~B})$ is an IFGCS in $\mathrm{X}$. Thus $\mathrm{f}$ is a IFG continuous mapping.

Proposition 4.4: A mapping $\mathrm{f:}(\mathrm{X}, \tau) \rightarrow(\mathrm{Y}, \sigma)$ be an IFW $\pi \mathrm{G}$ continuous mapping and $\mathrm{g}:(\mathrm{Y}, \sigma) \rightarrow(\mathrm{Z}, \delta)$ is

IF continuous, then $g \circ f:(X, \tau) \rightarrow(\mathrm{Z}, \delta)$ is an $\mathrm{IFW} \pi \mathrm{G}$ continuous.

Proof: Let D be an IFCS in Z. Then by definition $\mathrm{g}^{-1}(\mathrm{D})$ is an IFCS in $Y$. Since $f$ is an IFW $\pi \mathrm{G}$ continuous mapping, inverse image of a IFCS in $\mathrm{Y}$ is a IFW $\pi$ GCS in X. ie., $\mathrm{f}^{-1}$ 。 $\left(g^{-1}(D)\right)=(g \circ f)^{-1}(D)$ is an IFW $\pi$ GCS in X. Therefore $g \circ f$ is a IFW $\pi \mathrm{G}$ continuous mapping.

\section{CONCLUSION}

In this paper, a special type of IF cts mapping, namely IFW $\pi \mathrm{G}$ continuous mapping is introduced. Their relationships have been studied. Some of the basic properties of intuitionistic fuzzy weakly $\pi$ generalized continuous mapping are derived. Also the relationship among the intuitionistic fuzzy weakly $\pi$ generalized continuous mapping and other existing intuitionistic fuzzy continuous mappings are obtained. It is given, schematically in figure (3.1).

\section{REFERENCES}

[1] Atanassov.K.T, "Intuitionistic fuzzy sets", Fuzzy setsand systems, Vol.20, (1), (1986), 87-96.

[2] Bhattacharyya.P and Lahiri.B.K, "Semi generalizedclosed sets in topology", Indian Journal of Mathematics, Vol.29, (3), (1987), 375-382.
[3] Chang.C.L, "Fuzzy topological spaces", Journal of Mathematical Analysis and Applications, Vol.24, (1), (1968), 182-190.

[4] Dogan Coker, "An introduction to intuitionistic topological spaces", Fuzzy sets and systems, Vol.88, (1), (1997), 81-89.

[5] Gurcay.H, Coker.D, and Hydar.A "On fuzzy continuity in intuitionistic fuzzy topological spaces", The Journal of fuzzy mathematics, Vol.5, (2), (1997), 365- 378.

[6] Hanafy.I.M, "Intuitionistic fuzzy $\Upsilon$ continuity", Canadian Mathematical Bulletin. Vol.52, (4),(2009) 544-554.

[7] Kadambavanam.K and Vaithiyalingam.K, "Weakly $\pi$ Generalized Closed Sets in Intuitionistic Fuzzy Topological Spaces and its Applications", International Journal of Modern Sciences and Engineering Technology, Vol.3,(1),(2015), 45- 52.

[8] Mukundhan.C and Nagaveni.N, "A Weaker form of a Generalized closed set", International Journal of Contemporary Mathematical Sciences,Vol. 6,(20), (2011), 949-961.

[9] Sakthivel.K , "Intuitionistic Fuzzy Alpha Continuous Mappings and Intuitionistic Fuzzy Alpha Generalized Irresolute Mappings", Applied Mathematical Sciences, Vol.4,(37),(2010), 1831-1842.

[10] Santhi.R, and Sakthivel.K, "Intuitionistic Fuzzy Generalized Semi Continuous Mappings", Advances in Theoretical and Applied Mathematics,Vol. 5,(1),(2009), 73- 82.

[11] Sarsak, M.S, and Rajesh, N, " $\pi$ - Generalized Semi Preclosed Sets", International Mathematical Forum, Vol.5,(12), (2010), 573-578.

[12] Shyla Isac Mary.T, and Thangavelu.P, "On Rgular PreSemi Closed Sets in Topological Spaces", KBM Journal of Mathematical Sciences \& Computer Applications, Vol.1,(1),(2010), 9-17.

[13] Thakur.S.S and Rekha Chaturvedi, " Regular Generalized Closed sets in intuitionistic fuzzy topological spaces", Universitatea Din Bacau Studii Si Cercetari Stiintifice,Vol.16,(1),(2006), 257-272.

[14] Young Bae Jun and Seok -Zun Song , “ Intuitionistic fuzzy semi-preopen sets and Intuitionistic semiprecontinuous mappings", Journal of Applied Mathematics and Computing, Vol.19,(1), (2005), 464474.

[15] Young Bae Jun,Joung Kon Jeon and Jin Han Park , “ Intuitionistic fuzzy alpha continuity and Intuitionisticfuzzy pre continuity", International Journal of Mathematics and Mathematical Sciences, Vol.19,(2), (2005), 3091-3101.

[16] Zadeh.L.A, "Fuzzy sets", Information and control, Vol.8,(3),(1965),338-353. 